\title{
Ionic liquids in biotechnology: applications and perspectives for biotransformations
}

\author{
Christoph Roosen • Pia Müller • Lasse Greiner
}

Received: 2 April 2008 /Revised: 22 September 2008 / Accepted: 23 September 2008 / Published online: 21 October 2008

(C) The Author(s) 2008. This article is published with open access at Springerlink.com

\begin{abstract}
Ionic liquids are considered as an alternative to organic solvents for catalysis. The literature in this field is reviewed with focus on advantageous use of ionic liquids in biocatalysis and biotransformations. The overview reveals that the exploration and mapping of ionic liquids with respect to biocatalysis is still sketchy. It is apparent that advantages can be gained in view of activity, stability and selectivity. Furthermore, integration of reaction and separation has a high potential in the field. The review presents quantitative data on the productivities, space-time yields, as well as stability as far as they can be extracted from the literature.
\end{abstract}

Keywords Ionic liquids · Biocatalysis · Biphasic biocatalysis $\cdot$ Non-conventional media $\cdot$ Biotransformation

\section{Introduction}

A pure salt which is liquid below a threshold temperature (usually $100^{\circ} \mathrm{C}$ ) is denoted as an ionic liquid (IL). The use

Electronic supplementary material The online version of this article (doi:10.1007/s00253-008-1730-9) contains supplementary material, which is available to authorized users.

C. Roosen $\cdot$ P. Müller $\cdot$ L. Greiner $(\bowtie)$

Institut für Technische und Makromolekulare Chemie,

RWTH Aachen University,

Worringerweg 1,

52074 Aachen, Germany

e-mail: greiner@itmc.rwth-aachen.de

C. Roosen

Institut für Angewandte Polymerchemie,

University of Applied Science Aachen,

Worringerweg 1 ,

52074 Aachen, Germany of IL is of high current interest for catalysis (Parvulescu and Hardacre 2007), biocatalysis (Rantwijk and Sheldon 2007) and other applications are emerging. ILs are often discussed as the alternative to organic solvents in view of sustainable and ultimately "green" processes.

Some aspects of relevance for biocatalysis have not been reviewed critically so far: what advantages can be expected for biotransformations and catalysis? Does the current state of research substantiate the rise of big expectations for the application of IL in biocatalysis? Is the basis for technical application substantiated by enzyme performance and/or productivities? As metrics for technical applicability and comparison we have calculated the productivity per mass of enzyme preparation and space-time yields (STY) from the references whenever possible (for tables see the supporting information). The results vary more than three orders of magnitude and, therefore, allow a semi-quantitative comparison. Selected examples in view of technical applicability are given in more detail.

The definition of IL matches a broad variety of substances which not only in view of biocatalysis have little in common. The number of IL and their properties are at least as wide as the broad variety of solvents available today. An even qualitatively applicable structure-properties relationship does not exist so far (Bhargava et al. 2008). In particular, the miscibility of IL varies from virtually immiscible to fully miscible with water illustrating the range of different properties in view of biocatalysis.

Interaction with the (bio-)catalyst may lead to higher selectivities and stabilities enhancing productivities of the catalytic system. This has been shown for a broad number of biocatalysts and is known for conventional solvents as well. The present studies do support that the properties of IL can provide gains for activity, stability and separation as properties can be varied widely. Especially, separation can 
be facilitated by the inherently low vapor pressure of IL allowing for easy removal of volatile substances. This can be carried out by sublimation, distillation or extraction with supercritical fluids in which IL are virtually insoluble. The separation can be combined directly with the reaction in either continuous or batchwise applications. Here, IL can show selectivities which are difficult to obtain otherwise (Eckstein et al. 2006; Peters et al. 2007). However, the overall mapping of the biocatalysis in IL (Fig. 1) shows that the number of studies and their experimental approaches are not sufficient to support understanding of the influence of IL on even the most prominent biocatalysts used (see below).

So far, the early claims of generally favorable ecotoxicity and biodegradability of IL investigated is not substantiated and is reduced to the negligible low vapor pressure compared to organic solvents, and some authors postpone this aspect to further developments (Rantwijk and Sheldon 2007).

Of specific relevance are purity, water activity, analysis of IL as well as solutes of IL which are still not resolved generally. Particularly, trace impurities are known to have significant effects on (bio-)catalyst activity and stability (Park and Kazlauskas 2001). Therefore, synthesis related impurities as halide or silver ions are important and sometimes lead to poor reproducibility especially in early results in the field. This is addressed by either downstream purification (Nockemann et al. 2005) or optimised continuous synthesis (Minnich et al. 2007). As recognized early on for conventional solvents water is of importance for both activity and stability of biocatalysts. Here, the concept of water activity $a_{\mathrm{W}}$ as opposed to water content is of importance to gain basic understanding and to distinguish between effects from the solvents and the availability of water (Eckstein et al. 2006). Furthermore, the analysis of IL and solutes is no routine work and care has to be taken to obtain valid results (Baker et al. 2005).

The cations and anions in IL applied for biocatalysis found in the open literature are shown in Figs. 2 and 3, respectively. From the 20 cations and 26 anions yielding 520 combinations, only $11 \%$ have been applied so far; not taking into account cation and anion which have been shown to be IL but have to the best of our knowledge not been applied to biocatalysis. Therefore, the exploration map of biocatalysts probed in IL remains sketchy even more as the approaches taken by various groups render direct comparison difficult (Fig. 1). Expectably, the emphasis of the research carried out lies on commercially available IL. BMIM-based IL have gained the main attention with $\mathrm{BF}_{4}$ and $\mathrm{PF}_{6}$ and recently $\mathrm{NTF}_{2}$ and $\mathrm{OTF}$ as anions (see Fig. 2 and 3 for structures and abbreviations).
Fig. 1 Mapping of enzyme preparations in the matrix of anions and cations used for biocatalysis (see Figs. 2 and 3 for structures and abbreviations); the color coding refers to the number of different enzyme preparations used per ion combination, the length of the bars gives the count per ion

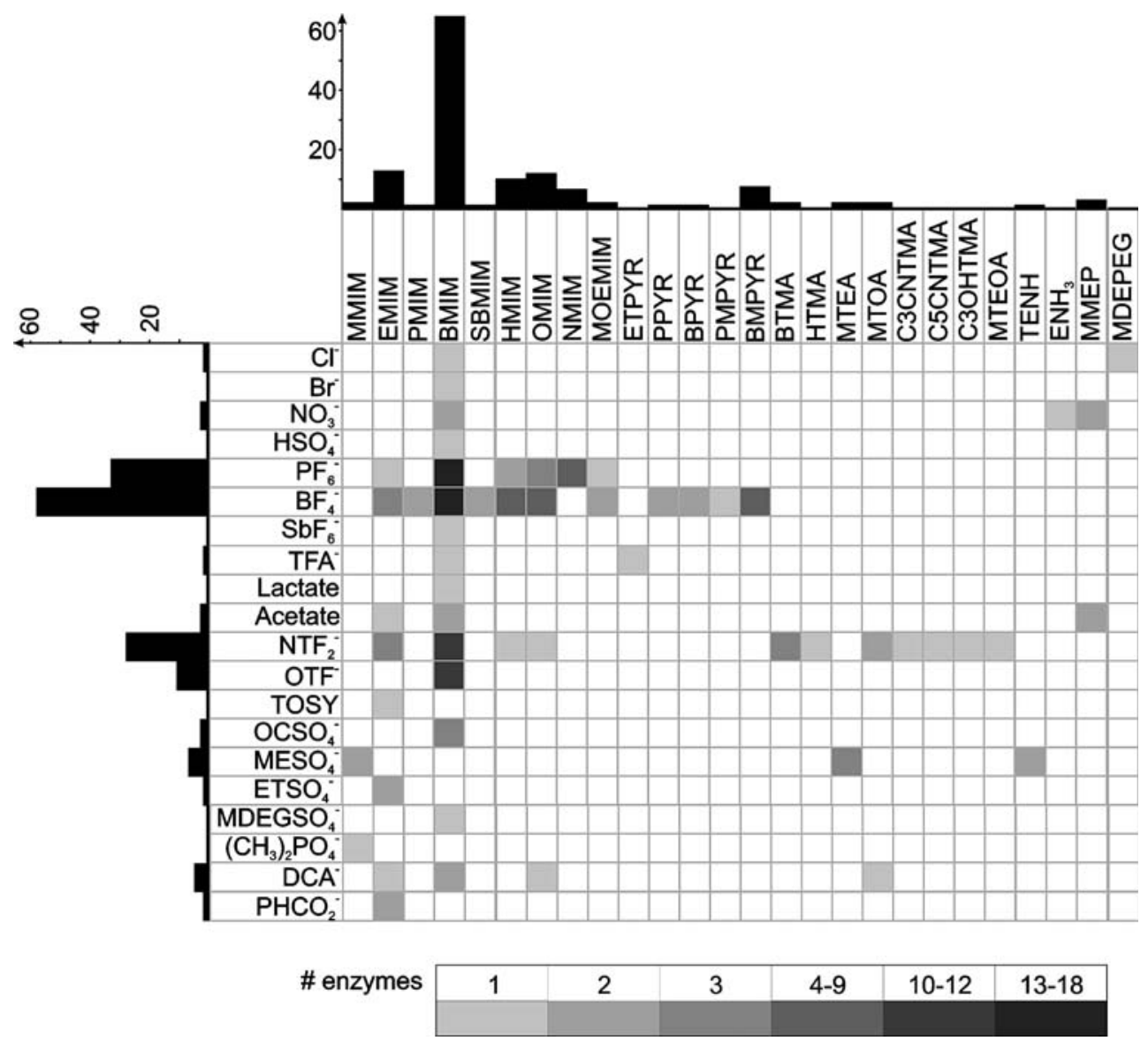




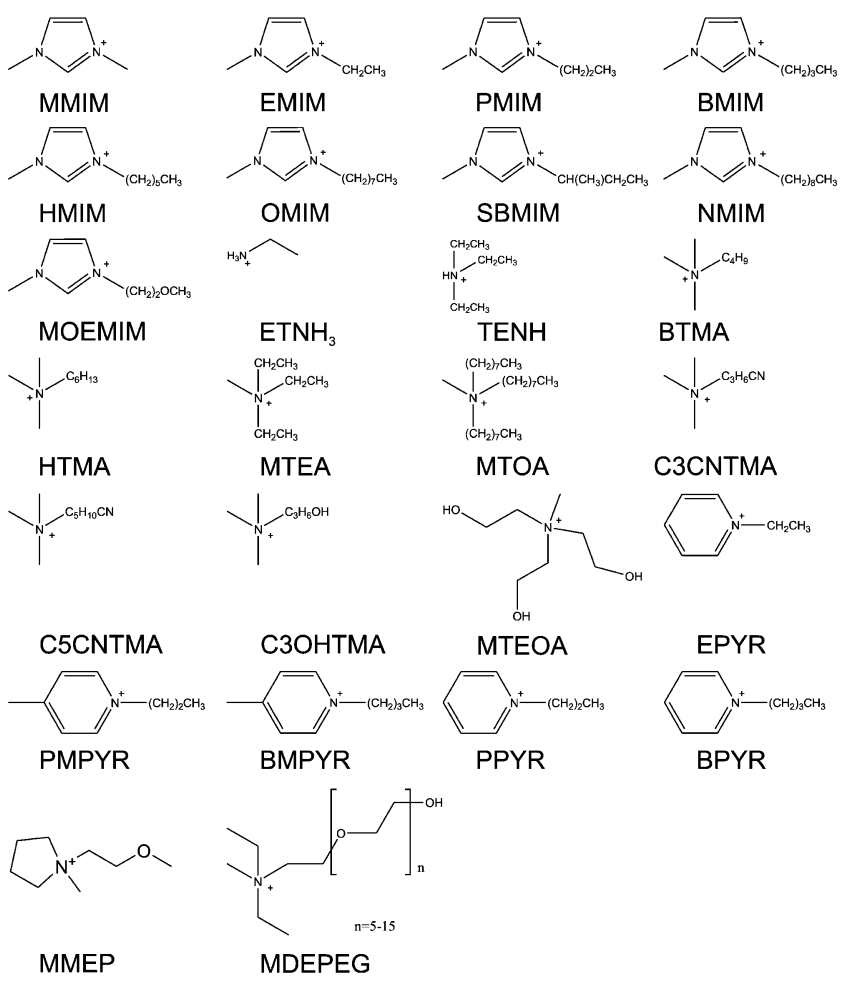

Fig. 2 Structures and abbreviations of IL cations applied in biocatalysis

As biocatalysts, mainly hydrolases (enzyme class 3) have been employed with Candida antarctica lipase B (CALB) in free form or an immobilised preparation accounting for more than $75 \%$ of the contributions to the field. Surprisingly, the role of enzyme preparation on performance is generally not addressed even though $\mathrm{pH}$ memory and additives are known to dominate activity and stability in conventional solvents when an insoluble enzyme is applied (Gupta 1992; Klibanov 1987).

The application of IL in monophasic systems is either as pure solvents or as miscible additives to aqueous buffer systems. For the use as pure solvent, only a few studies can be found that allow comparison on the basis of $a_{\mathrm{W}}$.

For the kinetic resolution of $(R, S)$-1-phenylethanol via transesterification with vinyl acetate catalysed by Pseudomonas sp. lipase (Chirazyme L-6) enantiomeric excess increased whereas conversion decreased with higher water activity for both methyl tert-butyl ether (MTBE) and $[\mathrm{BMIM}]\left[\mathrm{NTF}_{2}\right]$ (Eckstein et al. 2002). At the same initial $a_{\mathrm{W}}$ the catalytic activity was always higher in MTBE than in the IL, whereas selectivity was higher in the IL comparing the same level of conversion. In MTBE, the enzyme selectivity decreased fast above $50^{\circ} \mathrm{C}$ from an $E$ value of 270 to 4 whereas in the IL no loss of enantioselectivity was apparent for temperatures up to $70^{\circ} \mathrm{C}$ at $E=150$. The authors attribute the difference to the boiling point of either MTBE or of the reactants in the IL with the lowest boiling point (vinyl acetate).

Stabilisation of insoluble enzyme preparations by IL was reported by various groups. However, the majority of the reports are singular reports on enzymes and/or IL comparing only few conventional solvents. The earliest report was on thermolysin to be stabilised in [BMIM] $\left[\mathrm{PF}_{6}\right]$ compared to ethyl acetate (Erbeldinger et al. 2000). Furthermore, only a few studies take the effect of the enzyme preparation into account which has an impact as shown by the stabilisation of enzymes in a range of IL with cross linked enzyme aggregates (CLEA; Toral et al. 2007).

Storage stability of the commercial preparation of CALB in 1-butanol, hexane, $[\mathrm{EMIM}]\left[\mathrm{BF}_{4}\right],[\mathrm{EMIM}]\left[\mathrm{NTF}_{2}\right]$, $[\mathrm{BMIM}]\left[\mathrm{PF}_{6}\right]$, and $[\mathrm{BMIM}]\left[\mathrm{NTF}_{2}\right]$ was compared. [EMIM] $\left[\mathrm{BF}_{4}\right]$ led to a stabilisation with doubling half life to $8.3 \mathrm{~h}$ at $50^{\circ} \mathrm{C}$ (Lozano et al. 2001). The reason is obscured by the wide variation of $a_{\mathrm{W}}$ for the IL at the chosen constant water content of $2 \%(v / v)$. Interestingly, stability in IL generally increased in the presence of dissolved substrates to less than $5 \%$ loss of activity within $4 \mathrm{~h}$.

Increased stability was reported for Bacillus stearothermophilus esterase immobilised on celite in $[\mathrm{BMIM}]\left[\mathrm{PF}_{6}\right]$ compared to MTBE and hexane both at $\mathrm{a}_{\mathrm{W}}=0.11$; half life in MTBE and hexane was determined with $80 \mathrm{~h}$ and $8 \mathrm{~h}$, respectively, no inactivation in IL was observed within $240 \mathrm{~h}$ (Persson and Bornscheuer 2005). The authors attribute the stabilisation to electrostatic interactions between the IL and the enzyme. Candida rugosa lipase (CRL) was recycled five times in $[\mathrm{BMIM}]\left[\mathrm{PF}_{6}\right],[\mathrm{OMIM}]\left[\mathrm{PF}_{6}\right]$, as well as in organic solvents (toluene and hexane) with decreases in activity of $5 \%, 8 \%$ and $50 \%$, respectively, and a decrease of $15 \%$ for the enantioselectivity in IL as compared to more than $50 \%$ for both tested organic solvents (Persson and Bornscheuer 2005). Later, storage

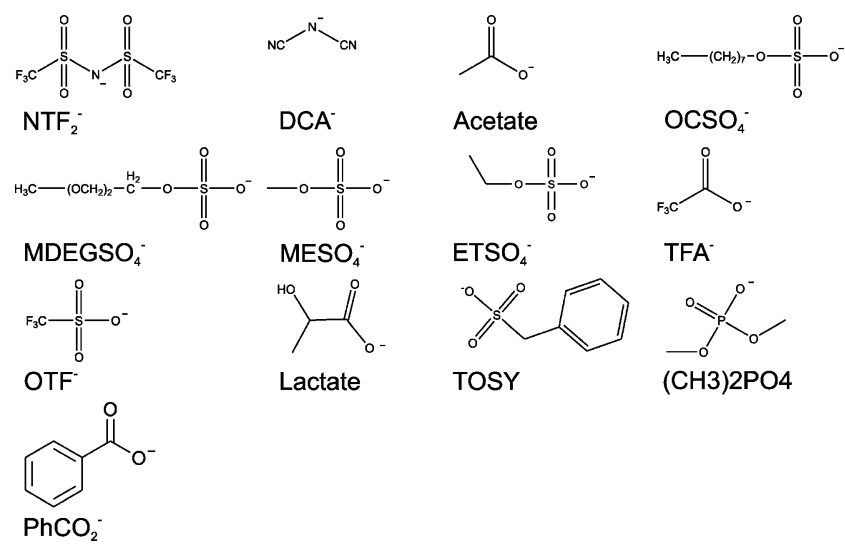

Fig. 3 Structures and abbreviations of IL anions applied in biocatalysis 
stability was determined as a function of temperature and $a_{\mathrm{W}}$. The highest half life at $a_{\mathrm{W}}=0.36$ were obtained for both hexane $(7.2 \mathrm{~h})$ and [OMIM] $\left[\mathrm{PF}_{6}\right](11.8 \mathrm{~h})$. The decrease in half life with temperature was lower in IL ([BMIM] $\left[\mathrm{PF}_{6}\right]$ and $\left.[\mathrm{OMIM}]\left[\mathrm{PF}_{6}\right]\right)$ than in the solvents hexane, dibutyl ether and benzene. The optimum $a_{\mathrm{W}}$ for stability was not altered significantly with temperature. The authors postulate a relation between the Reichardt's dye polarity and the decrease in half life with the temperature.

CALB storage stability was found to increase with the alkyl chain length of the MIM-based cation ([BMIM] $\left[\mathrm{PF}_{6}\right]$ $48 \mathrm{~h}$ to [OMIM][PF 6$] 84 \mathrm{~h}$; de los Riós et al. 2007), changing the anion from $\left[\mathrm{PF}_{6}\right]$ to $\left[\mathrm{NTF}_{2}\right]$ and $\left[\mathrm{BF}_{4}\right]$ with [HMIM] as cation decreases the half life from 78 to 72 to $7 \mathrm{~h}$, respectively. However, the authors kept water content constant at 2 vol.\% not allowing for comparison on basis of $\mathrm{a}_{\mathrm{W}}$ or even water molar fraction.

IL can solubilise enzymes. Mostly, this leads to rapid deactivation as for thermolysin which lost all of the minimum retained activity within minutes when dissolved in $[\mathrm{BMIM}]\left[\mathrm{PF}_{6}\right]$ (Erbeldinger et al. 2000). CALB was found active only in [MTEA] $\left[\mathrm{MeSO}_{4}\right]$ which was confirmed by minimal changes in the infrared spectrum of the dissolved enzyme (Rantwijk et al. 2006).

The role of trace impurities in IL was shown by using purified and non-purified [PMIM] $\left[\mathrm{BF}_{4}\right]$ for acylation with Pseudomonas cepacia lipase (Park and Kazlauskas 2001). After purification activity is comparable to toluene (productivity $4.9 \mathrm{~g} \mathrm{~g}^{-1}$ in $[\mathrm{BMIM}]\left[\mathrm{PF}_{6}\right]$ and $3.6 \mathrm{~g} \mathrm{~g}^{-1}$ in toluene) whereas the non-purified IL completely inhibited the lipase. The activity loss is mainly attributed to silver ions which are introduced by some synthesis protocols.

The activity and selectivity of CALB in 19 IL and hexane where compared for the transesterification of vinyl butyrate with 1-butanol (de los Riòs et al. 2007). A selectivity of $75 \%$ with STY of $11.2 \mathrm{~g} \mathrm{~L}^{-1} \mathrm{~h}^{-1}$ was found for hexane. In ten water-miscible IL selectivities greater than $99 \%$ with STY at least one order of magnitude lower were reported with the exception of [BMIM][DCA] at STY $=18.2 \mathrm{~g} \mathrm{~L}^{-1} \mathrm{~h}^{-1}$. The water-immiscible IL showed lower selectivity of $79 \%-94 \%$. However, the STY were generally higher (up to $170 \mathrm{~g} \mathrm{~L}^{-1} \mathrm{~h}^{-1}$ in $\left.[\mathrm{OMIM}]\left[\mathrm{PF}_{6}\right]\right)$ than in the water-immiscible ones. As mentioned above the comparability may be questioned due to the experimental approach of constant water content of 2 vol. $\%$.

The potential of IL as polar solvent for biocatalysis is demonstrated for polar substrates showing low solubility in enzyme compatible organic solvents. The acylation of the highly polar $\beta$-D-glucose catalysed by CALB is a model reaction. The comparably high solubility of the substrate allows for high productivity and space-time yield (STY) in IL (3.4 $\mathrm{g} \mathrm{g}^{-1}$ and $2.84 \mathrm{~g} \mathrm{~L}^{-1} \mathrm{~h}^{-1}$ in [MOEMIM] $\left.\left[\mathrm{BF}_{4}\right]\right)$ in which the highest regioselectivity ( $93 \%$ at $99 \%$ conversion) was observed (Itoh et al. 2001). Upon recycling of the enzyme-IL mixture by extraction with hexane for four times the enantioselectivity remained at $>99 \%$ but activity decreased 30-fold.

The regioselective acylation of $\beta$-D-glucose with CALB (Novozym SP435) in two different organic solvents (acetone, THF) and eight IL was carried out (Park and Kazlauskas 2001). Near quantitative conversion ( $99 \%$ ) was obtained in both THF and [MOEMIM] $\left[\mathrm{BF}_{4}\right]$ with higher regioselectivity (93 vs. $53 \%)$ and higher STY $\left(0.76 \mathrm{~kg} \mathrm{~L}^{-1} \mathrm{~h}^{-1}\right.$ vs. $0.43 \mathrm{~kg}$ $\mathrm{L}^{-1} \mathrm{~h}^{-1}$ ) in the IL. The highest regioselectivity of $99 \%$ was obtained in $[\mathrm{EMIM}]\left[\mathrm{BF}_{4}\right]$ with a conversion of $50 \%$ and comparable STY $=0.40 \mathrm{~kg} \mathrm{~L}^{-1} \mathrm{~h}^{-1}$.

The acylation of different glycosides catalysed by Candida rugosa lipase was carried out in THF and $\mathrm{CHCl}_{3}$ and compared within $[\mathrm{BMIM}]\left[\mathrm{PF}_{6}\right]$ and $[\mathrm{MOEMIM}]\left[\mathrm{PF}_{6}\right]$ (Kim et al. 2003). In both ILs, not only higher yields (e.g. $82 \%$ in $[\mathrm{BMIM}]\left[\mathrm{PF}_{6}\right]$ vs. $25 \%$ in $\mathrm{CHCl}_{3}$ ) but also higher regioselectivities (e.g. $90 \%$ vs. $77 \%$ ) were observed. Similarly, activity of glucose oxidase from Aspergillus niger and fungal peroxidase from Coprinus cinereus in [BMIM] $\left[\mathrm{PF}_{6}\right]$ could be found for water insoluble substrates (Okrasa et al. 2003).

For the synthesis of glucose fatty acid esters CALB was employed in IL as pure solvents ([BMIM] $\left[\mathrm{PF}_{6}\right]$ and [BMIM] $\left[\mathrm{BF}_{4}\right]$ ) and as mixture with $t$ - $\mathrm{BuOH}$ (Ganske and Bornscheuer 2005). Best results were obtained for the transesterification with myristic acid vinyl ester in [BMIM] $\left[\mathrm{BF}_{4}\right]$ with $40 \% t$ - $\mathrm{BuOH}(89 \%$ conversion and yield).

A number of investigations shows that IL as additive or solubiliser for aqueous systems can influence activity and selectivity and allows the conversion of otherwise insoluble substrates.

Comparing seven water-miscible MIM-based IL in different aqueous concentrations did also influence the selectivity of Novozym 435 catalysed hydrolysis of D,Lphenylglycine methyl ester (Lou et al. 2006). The anion $\mathrm{BF}_{4}^{-}$gave the best results in both initial reaction rate and selectivity. The best result was obtained with $20 \%(v / v)$ [BMIM] $\left[\mathrm{BF}_{4}\right]$ in phosphate buffer with an $E=34$ compared to aqueous phosphate buffer with $E=12$.

In 2007, Kroutil and co-workers (de Gonzalo et al. 2007a) reported on the stereoselective reduction of 2octanone by $E$. coli alcohol dehydrogenase ' $A$ ' in ILaqueous buffer mixtures. It was shown that an increase in the IL to buffer ratio leads to decrease in enzyme activity. Since these mixed phases allow for higher substrate concentrations, the maximum STY of the reaction could be increased fourfold to $2.2 \mathrm{~g} \mathrm{~L}^{-1} \mathrm{~h}^{-1}$ at a 2-octanone concentration of $1.2 \mathrm{~mol} \mathrm{~L}^{-1}$ with $90 \%(v / v)$ IL. However, in another report, the same authors report similar results by using micro-aqueous - organic solvent mixtures (de Gonzalo et al. 2007b). The hydrolysis of $N$-acetyl amino 
acid ethyl esters by Novo alcalase from Bacillus licheniforms (mainly subtilisin Carlsberg) in [EtPy][TFA]/water and acetonitrile/water (both $15 \%(v / v)$ ) was compared (Zhao and Malhotra 2002). All reported substrates were converted in the IL system whereas in acetonitrile/water mixture, no activity was observed. For other substrates enantioselectivity and activity were comparable in solvents or better in the aqueous IL system.

In 2008, Kragl and co-workers described the use of [MDEPEGA]Cl for the purification of two ADH from Lactobacillus brevis and a thermophilic bacterium (TADH), respectively (Dryer and Kragl 2008) The IL had a stabilizing effect on both enzymes during purification and for the T-ADH during the reduction of acetophenone. Furthermore, the IL acts as a solubiliser for the low water-soluble substrate. The enantiomeric excess was unchanged at $>99 \%$; STY was increased by a factor of 2.5 when using $10 \%(w / w)$ IL. With increased substrate concentration from $10 \mathrm{mmol} \mathrm{L}^{-1}$ to $60 \mathrm{mmol} \mathrm{L}^{-1} \mathrm{STY}$ was increased by a factor of 1.7. Enantioselectivity of the hydrolysis of butyl 2-(4-chlorophenoxy) propionate catalysed by the Candida rugosa lipase could be increased by the addition of IL to an aqueous buffer solution (Mohile et al. 2004). Increasing the IL to $50 \%(v / v)$ raised the ee from $47 \%$ to $>99 \%$. However, activity at these conditions was at least 12 -fold decreased.

Product removal by distillation is facilitated by the negligible vapor pressure of the majority of IL; by this means, recycling of the enzyme in the IL is possible to some extent.

Five IL were tested at initial $a_{\mathrm{W}}=0.2$ for the kinetic resolution of indinavir precursor by Candida antarctica lipase B (Lourenco et al. 2007). In [BMIM][DCA], the reaction proceeded without enantioselectivity but the highest activities were obtained in [MDEPEG][DCA] with up to $98 \%$ enantiomeric excess. The isolation of the product was simplified as it can be removed and recovered under reduced pressure and the IL could be reused once.

For the transesterification of 1-phenylethanol with vinyl acetate, eight different enzymes in ten different IL were investigated (Schöfer et al. 2001). For all but one lipase, best results were obtained in IL. Productivities up to $6.5 \mathrm{~g}$ $\mathrm{g}^{-1}$ and STY of $0.23 \mathrm{~g} \mathrm{~L}^{-1} \mathrm{~h}^{-1}$ were achieved. For CALB in $[\mathrm{BMIM}]\left[\mathrm{NTF}_{2}\right]$, the reuse of IL and lipase for three times with no apparent loss of selectivity and $10 \%$ loss per cycle in activity was demonstrated. The removal of the products was feasible by distillation under reduced pressure.

Biphasic reaction systems facilitate the combination of reaction and separation. For biocatalysis the scope of substrates is broadened and by the proper choice of reactive and non-reactive phase thermodynamic boundaries can be maximised (Eckstein et al. 2006; Peters et al. 2007). Unsurprisingly, numerous enzymatic reactions have been performed in biphasic systems with some examples for the beneficial application of IL. They are either employed in aqueous biphasic systems as non-reactive alternatives to non-miscible organic solvents, or as immobilisation matrix and extracted by organic solvents or supercritical fluids (SCF).

Whole cells of Rhodococcus R312 were compared for the transformation of 1,3-dicyanobenzene to 3-cyanobenzamide in water/toluene and in water/[BMIM] $\left[\mathrm{PF}_{6}\right]$ (Cull et al. 2000). Maximum conversion (44\%) and selectivity was found to be higher in the IL system. The initial activity was found to be ten-fold higher than that in the toluene system with no apparent loss within $90 \mathrm{~min}$ in the $[\mathrm{BMIM}]\left[\mathrm{PF}_{6}\right]$ system, whereas in the toluene system residual activity increased six-fold within the observation period. The authors do not quantify the contribution of phase transfer kinetics or aggregation phenomena.

The synthesis of isoamyl acetate with Novozym 435 suspended in IL and isoamyl alcohol/acetic acid/toluene/ water mixture as the non-reactive phase was compared for six IL of which three are non-miscible with the non-reactive phase (Fehér et al. 2008). Yields of $90 \%$ were obtained in $[\mathrm{BMIM}]\left[\mathrm{PF}_{6}\right]$ and $[\mathrm{HMIM}]\left[\mathrm{PF}_{6}\right]$ of which the first was chosen for cost considerations. The reactive phase was reused seven times without apparent loss of activity; however, $21 \%$ mass loss of IL is reported. The reaction was scaled up by a factor of 6.5 where the enzyme amount was increased by a factor of 32.5 . Here, the IL phase was reused ten times. The highest productivities of $23 \mathrm{~g} \mathrm{~g}$ (biocatalyst) $^{-1}$ (see supporting information) were obtained for the single-batch experiments.

The hydrolysis of 3,4,6-tri- $O$-acetyl-D-glucal catalysed by celite-supported Pseudomonas cepacia lipase was compared for the biphasic mixtures of buffer and [BMIM] $\left[\mathrm{PF}_{6}\right]$ or $[\mathrm{BMIM}]\left[\mathrm{BF}_{4}\right]$ and monophasic $\mathrm{THF} /$ buffer (Mohile et al. 2004). The regioselectivity was improved to $98 \%$ from $62 \%$ with comparable productivities for THF and [BMIM] $\left[\mathrm{PF}_{6}\right]$.

Alcohol dehydrogenase from Lactobacillus brevis (LB$\mathrm{ADH}$ ) was employed in biphasic systems consisting of an aqueous phase and $[\mathrm{BMIM}]\left[\mathrm{NTF}_{2}\right]$ or methyl tert-butyl ether (MTBE) (Eckstein et al. 2004, 2006). The reduction of 2-octanone to $(R)$-2-octanol using substrate-coupled regeneration of the cofactor NADPH was performed with ee $>99 \%$ and excellent selectivity in both systems. The partition coefficients of the co-substrate 2-propanol and the co-product acetone change from $\sim 1$ in the MTBE system to 0.4 for 2-propanol and 2.0 for acetone in the IL system thereby the limiting conversion is increased (Eckstein et al. 2006). A conversion of $88 \%$ is obtained within the $3 \mathrm{~h}$ compared to $61 \%$ in the system with MTBE. Unfortunately, 
stability of the enzyme is higher in the presence of MTBE with a half life of $>1,000 \mathrm{~h}$ as compared to the IL with $50 \mathrm{~h}$.

The combination of IL with SCF is particularly useful as the IL is not soluble in SCF. Therefore, the loss of IL is negligible. In the case of carbon dioxide as SCF, the usually high solubility in IL with mole fractions of more than 0.6 and the viscosity of the IL is decreased significantly (Aki et al. 2004). The combination of IL as reactive phase and SCF as non-reactive phase has been successfully applied to a range of catalytic systems. So far, only lipases have been employed as biocatalysts with CALB in various IL/carbon dioxide systems. This is probably due to the high stability of CALB towards supercritical carbon dioxide (Karmee et al. 2008).

CALB was suspended in IL on two different supports and was used in $4 \mathrm{~h}$ reaction-extraction cycles with $\mathrm{scCO}_{2}$ as non-reactive phase and stored for $20 \mathrm{~h}$ at room temperature (Lozano et al. 2002). The synthesis of butyl butyrate from vinyl butyrate and 1-butanol was most successful using $[\mathrm{BMIM}]\left[\mathrm{NTF}_{2}\right]$. The reaction resulted in selectivity $>95 \%$ and conversion $>50 \%$ and exceptional STY and productivity of $11 \mathrm{~kg}$ g(enzyme $)^{-1}$. At $40{ }^{\circ} \mathrm{C}$, no deactivation after $32 \mathrm{~h}$ reaction time is apparent.

Successively, five ammonium-based IL were tested for the continuous synthesis of butyl butyrate with $\mathrm{scCO}_{2}$. Partly purified Novozym $525 \mathrm{~L}$ was imposed to silica gel and successively mixed with IL. Best results were obtained for the use of [ $\left.\mathrm{C}_{4} \mathrm{TMA}\right]\left[\mathrm{NTf}_{2}\right]$ with reported synthetic yield of $59 \%$ and selectivity of $98.5 \%$ at comparable STY and productivity of $0.6 \mathrm{~kg}$ g(enzyme $)^{-1}$. Over reaction, time yield and selectivity increased slightly. The authors assume the water content as the dominating factor. Activity and stability tests showed that in all IL the enzyme was more active and more stable than in hexane. In IL no apparent deactivation was found.

The kinetic resolution of secondary alcohols in the system IL/ $\mathrm{scCO}_{2}$ was target of investigations of Reetz et al. (2002, 2003). For the batchwise reactions, rac-2-octanol and vinyl acetate were used as standard substrates in three different IL (anion: BMIM, cations: $\mathrm{PF}_{6}, \mathrm{BF}_{4}, \mathrm{NTF}_{2}$ ) and 3 different preparations of CALB (lyophilisate, Novozym 435, sol-gel immobilisate). Highest activity was obtained with the lyophilized preparation. Comparing IL best results were obtained with lipophilic non-coordinating anions. $\left[\mathrm{NTF}_{2}\right]$ led to the highest selectivity with quantitative selectivity, regardless of enzyme preparation. Noteworthy, enzyme activity was not altered in IL compared to isooctane. Further secondary alcohols were tested for the batchwise kinetic resolution using Novozym 435 and $[\mathrm{BMIM}]\left[\mathrm{NTF}_{2}\right]$. Different pressures and temperatures were applied for the extraction with $\mathrm{scCO}_{2}$. Selectivities around $95 \%$ could be reached. The mixture of IL and immobilized enzyme were able to be recycled several times without apparent loss of activity and selectivity. For the continuous process, transesterification of $r a c$-1-phenylethanol with vinyl laureate Novozym 435 was suspended in $[\mathrm{BMIM}]\left[\mathrm{PF}_{6}\right]$. The reaction was continuously operated for $112 \mathrm{~h}$. The average yield of the $(S)$-acylation product was $81 \%$ with selectivity close to unity. The IL-enzyme mixture was recycled with identical selectivity and activity proving the high long-term stability of the immobilized CALB under given process conditions. Follow-up work showed that similar results can be obtained using PEG instead of IL [Lit.].

In 2002, Iborra et al. (Lozano et al. 2002) used [EMIM] $\left[\mathrm{NTF}_{2}\right]$ and $[\mathrm{BMIM}]\left[\mathrm{NTF}_{2}\right]$ as reactive phase for the continuous kinetic resolution of $\mathrm{rac}-1$-phenylethanol with CALB. The enzyme was imposed to celite, suspended in $\mathrm{IL}$, and used in $4 \mathrm{~h}$ reaction-extraction cycles followed by $20 \mathrm{~h}$ of storage at room temperature. As non-reactive phase again $\mathrm{scCO}_{2}$ was used. Depending on temperature, selectivities in the range of $78 \%$ to $97 \%$ with conversions of $>35 \%$ were obtained. Good productivity and fair STY characterize the reaction.

This was extended to the continuous dynamic kinetic resolution of rac-1-phenylethanol in the system $\mathrm{IL} / \mathrm{scCO}_{2}$ (Lozano et al. 2006). Novozym 435 was combined with silica modified with benzenesulfonic acid (SCX) as racemisation catalyst. Both the chemical catalyst and the immobilized CALB were mixed with IL. As the mixture of both catalysts did not show any activity, they were physically separated by glasswool. In the plug-flow reactor, two layers of enzyme with one layer of SCX in between were used. The reactor was continuously operated for $5 \mathrm{~h}$. In both [EMIM] $\left[\mathrm{NTF}_{2}\right]$ and [BTMA] $\left[\mathrm{NTF}_{2}\right]$, the yield of the $(R)$-ester product reached its maximum of $76 \%$ compared to the maximum $50 \%$ in $\left[\mathrm{BMIM}^{\mathrm{B}}\left[\mathrm{PF}_{6}\right]\right.$ without racemisation catalyst. The coating of the SCX with IL enhanced selectivity. Although the combined catalysts showed higher activity and selectivity in IL than in hexane, only low STY and productivity could be observed in the system $\mathrm{IL} / \mathrm{scCO}_{2}$. By using a different immobilisation technique using purified Novozym $525 \mathrm{~L}$ on modified silica-C4 a yield of $78 \%$ of the desired $(R)$ product ( $e e=92 \%$ ) was observed with a more than 20 -fold increase in STY $=18 \mathrm{~g} \mathrm{~L}^{-1} \mathrm{~h}^{-1}$ and productivity of $1.7 \mathrm{~g} \mathrm{~g}$

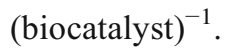

In conclusion, ILs extend the solvent range for biocatalysis in biphasic as well as monophasic systems. The examples highlight a potential in all relevant aspects of applications. IL may have significant impact on selectivity, stability and activity. Furthermore, no general trends can be identified for the interaction of biocatalysts and IL. Here, the database under experimentally comparable conditions has to be broadened considerably. Additionally, the peculiar role of water for biocatalysis has to be recognised and experimentally implemented. The identification and control 
of impurities is an aspect which is recognised generally. Especially the combination of reaction and separation will be of interest in the future as here the potential of IL can be exploited to full extent.

Acknowledgements For financial support, we thank the "Arbeitsgemeinschaft industrieller Forschungsvereinigungen" AiF (KF0174001UL5), the Ministry of Education and Research (BMBF, 17 55X 06) and Deutsche Forschungsgemeinschaft Graduiertenkolleg 1166 (BioNoCo). For helpful discussion we thank Prof. Walter Leitner (RWTH Aachen University).

Open Access This article is distributed under the terms of the Creative Commons Attribution Noncommercial License which permits any noncommercial use, distribution, and reproduction in any medium, provided the original author(s) and source are credited.

\section{References}

Aki SNVK, Mellein BR, Saurer EM, Brennecke JF (2004) Highpressure phase behavior of carbon dioxide with imidazoliumbased ionic liquids. J Phys Chem B 108:20355-20365.

Baker GA, Baker SN, Pandey S, Bright FV (2005) An analytical view of IL. Analyst 130:800-808

Bhargava BL, Balasubramian S, Klein ML (2008) Modelling room temperature ionic liquids. Chem Commun 7(29): $3339-3351$.

Cull SG, Holbrey JD, Vargas-Mora V, Seddon KR, Lye GJ (2000) Room-temperature IL as replacements for organic solvents in multiphase bioprocess operations. Biotechnol Bioeng 69:227233

de Gonzalo G, Lavandera I, Durchschein K, Wurm D, Faber K, Kroutil W (2007a) Asymmetric biocatalytic reduction of ketones using hydroxyfunctionalised water-miscible IL as solvents. Tetrahedron: Asymmetry 18:2541-2546

de Gonzalo G, Lavandera I, Faber K, Kroutil W (2007b) Enzymatic reduction of ketones in "micro-aqueous" media catalyzed by ADH-a from Rhodococcus ruber. Org Lett 9:2163-2166

de los Riós A, Hernández-Fernándes F, Martínez F, Rubio M, Víllora G (2007) The effect of IL media on activity, selectivity and stability of candida antarctica lipase $b$ in transesterification reactions. Biocatal Biotransform:151-156

Dreyer S, Kragl U (2008) Ionic liquids for aqueous two-phase extraction and stabilization of enzymes. Biotechnol Bioeng 99:1416-1424

Eckstein M, Sesing M, Kragl U, Adlercreutz P (2002) At low water activity/alpha-chymotrypsin is more active in an IL than in nonionic organic solvents. Biotechnol Lett 24:867-872

Eckstein M, Filho MV, Liese A, Kragl U (2004) Use of an IL in a twophase system to improve an alcohol dehydrogenase catalysed reduction. Chemical Communications:1084-1085

Eckstein MF, Peters M, Lembrecht J, Spiess AC, Greiner L (2006) Maximise equilibrium conversion in biphasic catalysed reactions: mathematical description and practical guideline. Adv Synth Catal 348:1591-1596

Erbeldinger M, Mesiano AJ, Russell AJ (2000) Enzymatic catalysis of formation of $Z$-aspartame in IL-an alternative to enzymatic catalysis in organic solvents. Biotechnol Prog 16:1129-1131

Fehér E, Illeová V, Kelemen-Horváth I, Bélafi-Bakó K, Polakovic M, Gubicza L (2008) Enzymatic production of isoamyl acetate in an ionic liquid-alcohol biphasic system. J Mol Catal, B Enzym 50:28-32
Ganske F, Bornscheuer UT (2005) Optimization of lipase-catalyzed glucose fatty acid ester synthesis in a two-phase system containing ionic liquids and $\mathrm{t}-\mathrm{BuOH}$. J Mol Catal B: Enzym $36: 40-42$.

Gupta MN (1992) Enzyme function in organic solvents. Eur J Biochem 203:25-32

Itoh T, Akasaki E, Kudo K, Shirakami S (2001) Lipase-catalyzed enantioselective acylation in the IL solvent system: reaction of enzyme anchored to the solvent. Chem Lett 30:262-263

Karmee SK; Casiraghi L, Greiner L (2008) Technical aspects of biocatalysis in non- $\mathrm{CO}_{2}$-based supercritical fluids. Biotechnol $\mathrm{J}$ 3:104-111

Kim M-J, Choi MY, Lee JK, Ahn Y (2003) Enzymatic selective acylation of glycosides in IL: Significantly enhanced reactivity and regioselectivity. J Mol Catal, B Enzym:115-118

Klibanov AM (1987) Enzymes that work in organic solvents. Chemtech 6:354-359

Lou W-Y, Zong M-H, Liu Y-Y, Wang J-F (2006) Efficient enantioselective hydrolysis of d,l-phenylglycine methyl ester catalyzed by immobilized Candida antarctica lipase b in IL containing systems. J Biotechnol:64-74

Lourenco NMT, Barreiros S, Afonso CAM (2007) Enzymatic resolution of indinavir precursor in IL with reuse of biocatalyst and media by product sublimation. Green Chem 9:734-736

Lozano P, de Diego T, Carrié D, Vaultier M, Iborra JL (2001) Overstabilization of Candida antarctica lipase b by IL in ester synthesis. Biotechnol Lett:1529-1533

Lozano P, de Diego T, Carrié D, Vaultier M, Iborra JL (2002) Continuous green biocatalytic processes using IL and supercritical carbon dioxide. Chem Commun:692-693

Lozano P, de Diego T, Larnicol M, Vaultier M, Iborra JL (2006) Chemoenzymatic dynamic kinetic resolution of rac-1-phenylethanol in IL and IL/supercritical carbon dioxide systems. Biotechnol Lett 28:1559-1565

Minnich CB, Küpper L, Liauw MA, Greiner L (2007) Combining reaction calorimetry and ATR-IR spectroscopy for the operando monitoring of IL synthesis. Catal Today 126:191-195

Mohile SS, Potdar MK, Harjani JR, Nara SJ, Salunkhe MM (2004) IL: efficient additives for candida rugosa lipase-catalysed enantioselective hydrolysis of butyl 2-(4-chlorophenoxy) propionate. J Mol Catal, B: Enzym:185-188

Nockemann P, Binnemans K, Driesen K (2005) Purification of imidazolium ionic liquids for spectroscopic applications. Chem Phys Lett 415:131-136

Okrasa K, Guibé-Jampel E, Therisod M (2003) IL as a new reaction medium for oxidase-peroxidase-catalyzed sulfoxidation. Tetrahedron: Asymmetry 14:2487-2490

Park S, Kazlauskas RJ (2001) Improved preparation and use of roomtemperature IL in lipase-catalyzed enantio- and regioselective acylations. J Org Chem 66:8395-8401

Parvulescu VI, Hardacre C (2007) Catalysis in IL. Chem Rev 107:2615-2665

Persson M, Bornscheuer UT (2005) Increased stability of an esterase from bacillus stearothermophilus in IL as compared to organic solvents. J Mol Catal, B Enzym:21-27

Peters M, Eckstein MF, Hartjen G, Spiess AC, Leitner W, Greiner L (2007) Exploring conversion of biphasic catalytic reactions: analytical solution and parameter study. Ind Eng Chem Res 46:7073-7078

Rantwijk FV, Sheldon RA (2007) Biocatalysis in IL. Chem. Rev 107:2757-2785

Rantwijk FV, Secundo F, Sheldon RA (2006) Structure and activity of Candida antarctica lipase b in IL. Green Chem $8: 282-286$

Reetz MT, Wiesenhöfer W, Francio G, Leitner W (2002) Biocatalysis in IL: batchwise and continuous flow processes using supercrit- 
ical carbon dioxide as the mobile phase. Chem Commun:992993

Reetz MT, Wiesenhöfer W, Francio G, Leitner W (2003) Continuous flow enzymatic kinetic resolution and enantiomer separation using IL/supercritical carbon dioxide media. Adv Synth Catal 345:1221-1228

Schöfer SH, Kaftzik N, Wasserscheid P, Kragl U (2001) Enzyme catalysis in IL: Lipase catalysed kinetic resolution of 1-phenyl- ethanol with improved enantioselectivity. Chem Commun:425426

Toral AR, Ríos APDL, Hernández FJ, Janssen MHA, Schoevaart R, Rantwijk FV, Sheldon RA (2007) Cross-linked Candida antarctica lipase $b$ is active in denaturing IL. Enzyme Microb Technol 40:1095-1099

Zhao H, Malhotra SV (2002) Enzymatic resolution of amino acid esters using IL $n$-ethyl pyridinium trifluoroacetate. Biotechnol Lett: $1257-1260$ 